www.volsu.ru

DOI: http://doi.org/10.15688/nav.jvolsu.2018.1.7

UDC 930.26(470+571)

LBC 63.48(2)

\title{
THE FORMATION OF THE SOURCE BASE OF SOKOLOVSKAYA BALKA TYPE MONUMENTS. SHILOV V.P.: THE ORDYNSKY BUGOR BURIAL MOUND ${ }^{1}$
}

\author{
Evgeniy V. Kruglov \\ Volgograd Regional Department of All-Russian Community for Nature and Culture Monuments Protection, \\ Volgograd, Russian Federation
}

\begin{abstract}
The paper is dedicated to the publication of materials on two barrows with two Khazar-era burials from the Ordynsky bugor burial mound. The archaeological site was located in the Chernoyarsky district of the Astrakhan region and was investigated by the Astrakhan archaeological mission of the Leningrad Department of the Institute of Archaeology, Academy of Sciences of the USSR in 1963. The mission was headed by Cand. Sc. (History) Valentin Pavlovich Shilov, and the scientific report on the investigation was written by Liya Yakovlevna Malovitskaya. The paper analyzes the grave goods from the burials: harness elements (stirrups), moulded vessels of the nomadic type, a compound bow. The most outstanding find is represented with the golden Arab dinar of al-Mansur dated by 143 (760/761 AD). Aleksey Andreevich Bykov, a numismatist and Orientalist, discovered that the dinar had a graffito on it, which was of particular importance. The author suggested a numismatic description of this coin. New photographs allowed to correct discrepancies of previous tracings of graffito on its surface and gave an opportunity to abandon its authentication as a runic character. The funeral rite helped to link the above-mentioned burials to burials of the Sokolovskaya balka type. The Ordynsky bugor burial mound is one of the very first burials of this type that were investigated. V.P. Shilov was the first to point out in a broadcast of A.A. Bykov that Sokolovskaya type burials contained remains of people of Turkic-Khazar origin. We suggest our own description for burials of this type and grounds for their cultural and chronological status. Turkic-Khazar ethnic authentication of antiquities of the Sokolovskaya type does not have any alternatives by now. The more difficult problem is the archaeological-cultural authentication of the above-mentioned monuments. Different chronology and asynchrony of monuments of the Sokolovskaya type (mid $7^{\text {th }}-$ early $9^{\text {th }} \mathrm{cc}$.) and of the Saltovo-Mayatsk culture ( $2^{\text {nd }}$ half of the $8^{\text {th }}-1^{\text {st }}$ half of the 10 th cc.) is an objective reality.
\end{abstract}

Key words: abbasid golden dinar, Khazar era, Khazars, burials of the Sokolovskaya balka type, the SaltovoMayatsk culture, Ordynsky bugor burial mound, Astrakhan archaeological mission, V.P. Shilov.

Citation. Kruglov E.V., 2018. The Formation of the Source Base of Sokolovskaya Balka Type Monuments. Shilov V.P.: the Ordynsky Bugor Burial Mound. The Lower Volga Archaelogical Bulltin, vol. 17, no. 1, pp. 144-159. (in Russian).

УДК 930.26(470+571)

ББК 63.48(2)

\section{ФОРМИРОВАНИЕ ИСТОЧНИКОВОЙ БАЗЫ ПАМЯТНИКОВ ТИПА СОКОЛОВСКОЙ БАЛКИ. ШИЛОВ В.П.: КУ РГАННЫЙ МОГИЛЬНИК ОРДЫНСКИЙ БУГОР 1}

\section{Евгений Викторович Круглов}

Волгоградское региональное отделение Всероссийского общества охраны памятников истории и культуры, г. Волгоград, Российская Федерация

Аннотация. Статья посвящена публикации материалов двух курганов с погребениями хазарского времени из могильника Ордынский бугор. Памятник располагался на территории Черноярского района Астра- 
ханской области и был исследован Астраханской археологической экспедицией ЛОИА АН СССР в 1963 г. Начальником экспедиции являлся кандидат исторических наук Валентин Павлович Шилов, автором научного отчета о раскопках - Лия Яковлевна Маловицкая. В статье проанализирован вещевой инвентарь из погребений: предметы сбруи (стремена), лепные сосуды «кочевнического» типа, сложносоставной лук. Наиболее примечательной находкой стал золотой арабский динар ал-Мансура Аббасида 143 г. (760/761 гг.). Особое значение имеет открытие нумизматом-востоковедом Алексеем Андреевичем Быковым граффито на этой монете. Автор предложил нумизматическое описание этой монеты. Новые фотографии позволили исправить неточности прежних прорисовок граффито на его поверхности и дали возможность отказаться от его атрибуции в качестве знака рунической письменности. Погребальный обряд позволил связать публикуемые захоронения с памятниками типа Соколовской балки. Ордынские бугры - одни из самых первых исследованных погребений этого типа. В.П. Шилов - первый, кто в передаче А.А. Быкова указал на тюрко-хазарскую этническую принадлежность погребенных из могил соколовского типа. Автор предложил свой вариант характеристики погребений этого типа и обосновал их культурно-хронологический статус. Тюрко-хазарская этническая атрибуция древностей соколовского типа в настоящее время уже не имеет альтернатив. Более сложной оказалась проблема археолого-культурной атрибуции обсуждаемых памятников. Разная хронология и асинхронность памятников соколовского типа (середина VII - начало IX в.) и салтово-маяцкой культуры (2-я половина VIII - 1-я половина Х в.) - объективная реальность.

Ключевые слова: аббасидский золотой динар, хазарское время, хазары, погребения типа Соколовской балки (соколовского типа), салтово-маяцкая культура, курганный могильник Ордынский бугор, Астраханская археологическая экспедиция, В.П. Шилов.

Цитирование. Круглов Е. В., 2018. Формирование источниковой базы памятников типа Соколовской балки. Шилов В.П.: курганный могильник Ордынский бугор // Нижневолжский археологический вестник. T. 17,№ 1. С. 144-159.

Погребения типа Соколовской балки устойчивая группа степных восточноевропейских захоронений рубежа VII/VIII - начала IX в., произведенных по обряду трупоположения человека с конем и (или) бараном (целым остовом и (или) шкурой), как правило, в могилах с подбоями, вырезанных в длинных, в основном южных стенках входных ям. Это определение позволяет учитывать максимально возможные виды однотипных могил: основные под курганами; впускные в курганах, дюнах, бэровских буграх; а также достоверно грунтовые ямные (бескурганные). Оно уходит и от необходимости оценки некоторых надэтнических признаков, в частности - так называемых внутренних ровиков, отражавших проведение не погребальных, а растянутых во времени поминальных действий [Круглов, 2013, с. 78, 82].

Самые первые подкурганные погребения, рассматриваемые в качестве памятников типа Соколовской балки, исследованы профессором Саратовского университета П.С. Рыковым в 1935 г. на территории Калмыкии в курганах 13 и 18 из урочища Три Брата. П.С. Рыков успел оценить своеобразие обнаруженных им памятников и связал их с печенегами [Рыков, 1936, c. 109]. Полноценно опубликовать полученные материалы и обосновать вывод об их этничес- кой атрибуции ему помешал арест и трагическая гибель в сталинских лагерях. И хотя научный отчет о раскопках П.С. Рыкова был доступен, сами материалы в целом оставались малоизвестными.

После 1935 г. новые подкурганные захоронения хазарского времени были обнаружены лишь в 1963 г. Новочеркасская экспедиция ЛОИА АН СССР (рук. С.И. Капошина) в кургане 8 Грушевского могильника на Нижнем Дону исследовала окруженную ровиком площадку подквадратной формы с полностью разрушенным погребением. В том же году Астраханская экспедиция ЛОИА АН СССР (рук. В.П. Шилов) на Нижней Волге в курганах 4 и 13 могильника Ордынский бугор обнаружила сразу два, что очень важно, ничем не потревоженных захоронения. Эти исследования проводились по открытому листу на имя Л.Я. Маловицкой [Маловицкая, 1963] и до сих пор не опубликованы. Наша работа отчасти призвана устранить это недоразумение. К сожалению, не все источниковедческие вопросы удалось закрыть.

Могильник Ордынский бугор состоял из 15 насыпей, вытянутых по линии 3-В и располагавшихся в 9 км к 3 от с. Соленое Займище Черноярского района Астраханской области. 
По краям и в центре группы располагались наиболее крупные курганы 7, 12 и 15. Экспедицией были раскопаны лишь девять самых мелких насыпей: 1-6, 8, 13-14 (рис. 1,I). Обнаруженные погребения в основном относились к раннему железному веку.

Курган 4 располагался в центре могильника, к ЮВ от основной группы (рис. 1,I). Его диаметр 24 м, высота 0,25 м. Насыпь состояла из дерна (рис. 1,II). Погребение совершено в могильной яме, ориентированной по линии ЮЗ-СВ. Ее размеры: $2,1 \times 0,75 \times 1,85$ м. В юго-восточной стенке вырезан подбой, дно которого ниже дна входной ямы на 0,3 м. Общая глубина могилы - 2,15 м. Размеры камеры 2,2 × 0,8, высота свода - 1,5 м (рис. 1,III).

На дне входной ямы располагались кости черепа (в ЮЗ части) и скаковые конечности (в СВ части) сложенной шкуры коня $(\text { пл. } 3)^{2}$. Передние конечности отчленены по пястной сустав, задние - по плюсневой и пяточный. Рядом с черепом коня располагались череп и кости передних конечностей барана (пл. 4), его задние конечности находились рядом со сложенной шкурой коня (рис. 1,III, 2,1).

В челюстях черепа коня зажаты железные удила, сохранившиеся в обломках (пл. 1). Между черепом и передними конечностями барана лежало железное арочное стремя с плоской прямоугольной опорной площадкой и выделенной трапециевидной петлей для ремня путалища (пл. 2). Высота стремени - 21 см, ширина 14 см, ширина опорной площадки - 3-4 см.

На дне подбоя, вытянуто на спине, располагался скелет взрослого мужчины (определение автора раскопок). Череп обращен на ЮЗ, лицевой стороной ко входу. Кости левой руки согнуты в локте, кисть - на тазовых костях. Кости ног слегка согнуты в коленях влево (рис. 1,III, 2,2).

За черепом погребенного, в дальнем углу подбоя, находился глиняный лепной сильно асимметричный плоскодонный кувшин яйцевидной формы с небольшим сливом и ручкой, отбитой еще в древности (пл. 6). Широкое низкое горло украшено по срезу венчика пальцевыми защипами. Поверхность покрыта хаотичными бороздками со следами заглаживания травой. Дно неровное, вогнутое. Высота 20-21,5 см; диаметры: тулова - 14 см, дна 8,6 см. Толщина стенок $-1 \mathrm{~cm}$, дна -2 см (рис. 4,4). На кувшине сверху лежал желез- ный однолезвийный нож с прямой спинкой и черенком (пл. 11). Длина сохранившейся части -9 см. Между черепом погребенного и кувшином располагались позвонки и ребра грудного отдела скелета барана (пл. 10), являвшиеся «заупокойной пищей». На тазовых костях погребенного, справа, лежала железная круглая пряжка со следами ткани (пл. 9). Ее диаметр - 4 см. Между фалангами пальцев кисти левой руки найден золотой арабский динар (пл. 5) (рис. 4,1-2). С наружной стороны локтевой кости левой руки лежал костяной кистень яйцевидной формы (пл. 8). Его длина $-8,5$ см, диаметры - 1,3 и 2,1 см. Над коленями, выше и вдоль бедренной кости, за ступнями левой ноги располагались остатки лука: три концевые и три срединные, две боковые и одна фронтальная роговые накладки (пл. 7). Длина срединной боковой пластины $-14,7$ см.

Курган 13 также был расположен в центре могильника. Он находился на расстоянии 220 м от кургана 4. Его диаметр - 16 м, высота 0,25 м. Насыпь состояла из дернового слоя (рис. $1, I V$ ). Погребение обнаружено в ЮВ секторе. Могильная яма ориентирована по линии Ю3-СВ. Ее размеры: 2,3 × 0,5 × 1,75 м. В юговосточной стенке вырезан подбой, дно которого находилось ниже дна входной ямы на 0,5 м. Общая глубина могилы - 2,25 м. Размеры камеры $2,7 \times 1,2$ м; высота свода - 1,5 м (рис. $1, V$ ).

На дне подбоя, у дальней стенки, вытянуто на спине располагались останки скелета взрослого мужчины, обращенного черепом на Ю3. Левая рука согнута в локте, кисть ее находилась на тазовых костях (рис. $1, V, 3,2$ ). Слева от погребенного лежали череп (в Ю3 части) и кости скаковых конечностей (в центре и СВ части) растянутой шкуры коня (пл. 5). Передние конечности коня отчленены по пястной сустав, задние - по плюсневой (рис. 3,1 ).

В челюстях черепа коня находились обломки железных кольчатых удил (пл. 4). Около передних конечностей лежало железное арочное стремя с плоской опорной площадкой и выделенной трапециевидной петлей для ремня путалища (пл. 3). Высота стремени - 20 см, ширина -13 см, ширина опорной площадки $-5 \mathrm{~cm}$.

Между передними конечностями коня и костями левой ноги погребенного располагались череп и передние конечности барана (пл. 6). Задние конечности барана находились 
рядом с задними конечностями коня (рис. 3,1 ). Между черепом коня и останками верхней части скелета погребенного также лежали кости конечностей второго барана (пл. 7 и 8). Слева от бедренной кости погребенного, рядом с черепом барана, найден каменный кистень овальной формы (пл. 1). Здесь же находилась железная прямоугольная пряжка длиной 3,5 см (пл. 2). За черепом погребенного, в южном углу камеры подбоя, стоял глиняный лепной баночный сосуд тюльпанообразной формы с широким плоским дном и низким горлом (пл. 13). Края сосуда отогнуты наружу, венчик неорнаментирован, тесто рыхлое, с примесями. Высота 21 см; диаметры: по краю венчика - 15,0 см, тулова $-17,5$ см, дна 12,5 см (рис. 4,5). Рядом с сосудом располагались поясничные позвонки и крестец крупного животного, коня или коровы, являвшиеся «заупокойной пищей» (пл. 9). Рядом с ними лежали обломки железного однолезвийного ножа с прямой спинкой и черенком для рукояти (пл. 12). Под позвонками и крестцом животного лежал прямоугольный точильный камень, четырехгранный в сечении (пл. 14). Длина изделия - 7 см. В заполнении, над черепом человека, найдены две четырнадцатигранные бусины из непрозрачного голубого стекла, длиной 1,1 см (пл. 11). Между черепами коня и погребенного на общем плане могилы отмечен также и пл. 10, но в самом отчете информации о нем нет.

Научный отчет Л.Я. Маловицкой, к сожалению, сопровождается фотографиями только сосудов и монеты и не дает представления об остальных предметах ${ }^{3}$.

Оба сосуда, горшок и кувшин, относятся к разным вариантам лепной кухонной посуды так называемого «кочевнического» типа. Они имеют характерное тулово, плоское дно, слабо профилированные венчики. Тесто рыхлое, многослойное, с примесью дресвы, рубленой травы и, возможно, мела. Обжиг костровой, неравномерный. В своих работах С.А. Плетнева подобную керамику определяла в качестве салтово-маяцкой. Вместе с тем она неизменно подчеркивала, что внешний вид этой керамики мало чем отличается как от более ранней лепной «сарматской или аварской» посуды, так и от более поздней «печенежской» или «половецкой» [Плетнева, 1967, с. 103-104]. Техно- логия изготовления лепной кухонной посуды раннего средневековья до сих пор практически не изучена. Редкие современные исследования показали существование не только разных традиций изготовления такой посуды, но и факты ее использования также и некочевническими группами населения Восточной Европы, в частности аланами [Афанасьев, 2013, с. 3450]. Баночный горшок из погребения кургана 13 в целом характерен для погребений типа Сoколовской балки, но лепные кувшины среди них - крайне редкая форма. В то же время украшение среза венчика пальцевыми защипами - один из основных характерных признаков именно соколовской лепной посуды. В целом оба сосуда относятся к варианту, у которого наиболее широкая часть тулова несколько приподнята, а диаметр по венчику чуть больше диаметра дна [Круглов, 1990, с. 161].

Судя по описанию, стремена из погребений относятся к типу Б II, широко распространенному в памятниках VIII-IX вв., в первую очередь связанных с древностями салтовомаяцкой культуры [Федоров-Давыдов, 1966, с. 11; Плетнева, 1967, с. 167]. Однако ареал этих стремян существенно шире. Кистени до сих пор считаются крайне редкой находкой в погребениях кочевников [Федоров-Давыдов, 1966, с. 32; Плетнева, 1967, с. 160]. Отметим, что железный кистень был найден в однокультурном погребении из кургана 11 Соколовского могильника [Круглов, 2013, с. 76, рис. 2,27].

Лук из погребения кургана 4 определяется как сложносоставной. Наличие трех роговых накладок одного края и трех накладок рукояти говорит о том, что он, возможно, был помещен в могилу сломанным, с утратой одного плеча. Сохранившееся указание на длину срединных накладок рукояти (14,7 см) наиболее ценно, так как при полном отсутствии каких-либо фотографий одно лишь это позволяет уверенно определять данное оружие в качестве лука «хазарского» типа [Круглов, 2005, с. 7981]. Такой лук появился на рубеже VII-VIII вв. на основе конструктивно-технологической трансформации более раннего лука «тюркохазарского» типа середины - 2-й половины VII в. и использовался в течение всего VIII в. населением, связанным с Хазарским каганатом. Поскольку технологическое развитие лука «хазарского» типа шло по линии уменьшения 
длины роговых накладок рукояти с 20 до $11 \mathrm{~cm}$, оружие из Ордынского бугра могло быть изготовлено лишь около середины VIII в. Вероятной аналогией ему является лук из погребения кургана 11 Соколовского могильника [Круглов, 2013 , с. 76 , рис. 2,2-4].

Наиболее примечательной находкой в рассматриваемых материалах является золотой арабский динар из погребения кургана 4, который, скорее всего, является классическим «оболом мертвого» (рис. 4,1,2). До настоящего времени монета полноценно не издана и даже не описана, ее лицевая сторона публикуется впервые (рис. 4,1a,2a). Место хранения: АГОИАМЗ, инв. № АМЗ КП 12072, передана В.П. Шиловым по акту № 650 от 22 июня 1964 г. Диаметр 1,8 см, вес 4,0 г. Описание монеты проводится по фотографиям ${ }^{4}$. Большую часть надписей составляют суннитские коранические цитаты. Описание типа с транслитерацией легенд в прочтении VIII в. и перевод с арабского Вяч.С. Кулешова.

Лицевая сторона. В поле надпись в три строки: lā ?ilāha ?illā / llāhu wahda-hū / lā šarīka la-hū /«Нет божества, кроме / Аллаха единого, / нет Ему сотоварища» (Коран, 47.21). Надпись по кругу (начало в позиции 14.00): Muhammadun rasūlu llāhi ?arsala-hū bi-l-hudā wa-dīni l-ḥaqqi li-yuẓhira-hū Salā d-dīni kulli-hī/ «Мухаммад посланник Аллаха, которого Он послал с руководством и истинной верой, чтобы возвеличить ее над всеми верами» (Коран, 9.33) (рис. 4,1a,2a).

Оборотная сторона. В поле надпись в три строки: Muhammadun / rasūlu / ḷāh / «Мухаммад посланник Аллаха» (Коран, 48.29). Надпись по кругу (начало в позиции 14.00): bi-smi llāhi dụriba hā-d̄ā d-dīnāru sanata talāta waTarba §ina wa-mi ?a / «Именем Аллаха бит этот динар года сто сорок третьего» (рис. 4,16,26).

В отчете Л.Я. Маловицкой динар имел широкое определение - середина VIII в. [Маловицкая, 1963, с. 48]. По информации В.В. Кропоткина, в качестве анонимного динара ал-Мансура Аббасида 143 г. (760/761 гг.) монету определил нумизмат-востоковед А.А. Быков [Кропоткин, 1968, с. 77, сноска 22]. Однако Г.А. Федоров-Давыдов уже в 1966 г. не только учитывал материалы обоих погребений, но и ввел соответствующее определение монеты в научный оборот [Федоров-Да- выдов, 1966, с. 254, № 267г, 267д, с. 264, прил. 5]. Краткую характеристику погребения из кургана 4, полученную от В.П. Шилова, определение динара, фотографию его оборотной стороны А.А. Быков опубликовал лишь в 1974 г. [Быков, 1974, вклейка между с. 32-33, рис. 19, с. 59]. Для своей статьи, в целом посвященной анализу монет хазарской чеканки из Девицкого клада, А.А. Быков использовал фотографию из отчета Л.Я. Маловицкой, полученную от В.П. Шилова. Исследователь отметил, что монеты этого типа были известны уже В.Г. Тизенгаузену, который, в свою очередь, не давая изображений, указывал на еще более ранние находки, известные ему из трудов уже своих предшественников, знаменитых академиков-энциклопедистов Петербургской Академии Наук первой половины XIX в. - Х.Д. Френа, Б.А. Дорна и др. [Тизенгаузен, 1873, с. 71, № 719].

В своем сообщении А.А. Быков привлек сведения востоковеда-арабиста Р.Р. Фасмера о соотношении стоимости серебра и золота в VIII в. Если в последние годы VII в. и в начале VIII в. золото в Халифате ценилось в десять раз дороже серебра, то около 800 г. за один динар давали уже от 20 до 22 серебряных дирхемов. Основываясь на этом, А.А. Быков сделал вывод о том, что золотая монета подчеркивала особый статусный характер всего погребения и указывала на то, что ее владелец при жизни был весьма богатым человеком и, вероятно, не самым простым воином [Быков, 1974, с. 59].

В настоящее время на территории Восточной Европы зафиксировано 14 случаев находок золотых куфических монет VIII в. из 9 местонахождений (11 динаров и 3 подражаний динарам). На территории Хазарского каганата локализуется 13 монет, а единственным исключением является динар из Ладоги - древнейшего центра Русского государства [Кулешов, 2009, с. 59-61].

Распространение куфических монет на территории Хазарского каганата начинается на рубеже 750-760-х гг. [Круглов, 2004, с. 5254]. Отчасти это совпадает с появлением в донецко-донском бассейне классических памятников салтово-маяцкой культуры. В современной концепции многоэтапной хронологии обращения монет Халифата на территории 
Восточной Европы динар из Ордынского бугра занимает почетное место в самом начале ступени А (ок. 750/760-780/790 гг.) [Кулешов, 2016, с. 172]. Но арабские монеты появились в каганате отнюдь не внезапно и не случайно, они пришли на смену золотым византийским солидам, поступавшим в степь в середине VII - 1-й половине VIII в. [Круглов, 2002, с. 7993] ${ }^{5}$. Очевидно, что тюркюто-хазаро-болгарская кочевая элита Хазарского каганата, близко познакомившаяся с византийским золотом еще в середине VII в., испытывала устойчивую личную потребность в получении престижной и сакральной иноземной монеты и после разрыва хазаро-византийских политических отношений в середине VIII в.

В своей публикации А.А. Быков также сообщил о наличии на поверхности оборотной стороны динара граффито, располагавшегося в поле между центральной и круговой легендами и ввел в научный оборот его прорисовку [Быков, 1974, с. 59] (рис. 4,3a). По мнению исследователя, граффито являлось личным знаком собственности. Открытие граффито, для первой половины 1970-х гг. нового типа исторического источника, расширило горизонты научного интереса к монете из Ордынского бугра. До настоящего времени она остается единственным паспортизованным золотым куфическим динаром с граффито на всей территории Восточной Европы, что подчеркивает особую уникальность данной находки. Однако история изучения этого граффито больше похожа на детективное расследование.

В своде граффити, составленных на основе изучения восточных монет из фондов Государственного Эрмитажа [Добровольский и др., 1981, с. 54-55, табл. І,№ 20, 72-73, прил., № 20], позиция Ордынского бугра была проиллюстрирована заведомо фантастическим изображением (рис. 4,3б). В каталоге граффити на монетах Древней Руси и сопредельных стран ошибка была исправлена на основе прорисовки, изданной А.А. Быковым (рис. 4,3в), при этом само граффито получило статус тюркской руны [Добровольский и др., 1991, с. 9-10, 32, 134,№ 3, 164,№ 3]. В последнее время востоковед-арабист Вяч.С. Кулешов определил данное граффито как одну из наиболее ранних восточноевропейских надписей. По Вяч.С. Кулешову, она представляет собой соединение знака «И» со знаком «М». Кочевническая принадлежность погребения позволила автору считать эти знаки вариантом орхоно-енисейских тюркских рун [*a] и [*lt], а саму лигатуру - руническим граффито «ИМ» [*alt] и интерпретировать ее как тюркское [*altun] «золото; золотая монета; золотой» [Кулешов, 2012, с. 219].

Однако в ходе изучения черно-белой фотографии из научного отчета Л.Я. Маловицкой [Маловицкая, 1963, рис. 96] (рис. 4,1аб) оказалось, что реальные особенности данного граффито (рис. 4,32 ) не совпадают с прорисовкой А.А. Быкова (рис. 4,3a). Это подтвердили фотографии, а позднее и сканированные изображения современного вида динара, полученные автором из АГОИАМЗ (рис. 4,2aб,3d). Их изучение показало, что при горизонтальном расположении вместо знака «И» уверенно просматривается знак «V», имеющий несколько иной наклон относительно соседнего знака, который, в свою очередь, читается не в виде «М», а в виде двух отдельных знаков «Л». При этом первая «Л» соприкасается с «V», составляя единую пару знаков, а вторая «Л», имеющая раздвоенную ножку, явно отделена от первой (рис. 4,3d).

Уточнение внешнего вида граффито динара из Ордынского бугра вызвало необходимость оценки возможности его атрибуции. По мнению Вяч.С. Кулешова и И.Л. Кызласова, любезно ознакомившихся с имеющимися в нашем распоряжении материалами, граффито на данной монете не является руническим знаком. Несмотря на наличие сразу трех последовательно расположенных графических сюжетов, все интерпретации, ранее высказанные на основе степных рунических письменностей, следует считать ошибочными, а возможность какого-либо осмысленного чтения признать маловероятной ${ }^{6}$.

С подкурганными погребениями средневековых восточноевропейских кочевников В.П. Шилов впервые тесно соприкоснулся в 1952-1955 гг., когда возглавляемый им 4-й отряд Сталинградской археологической экспедиции Института Археологии АН СССР проводил в Заволжье охранные исследования Калиновского курганного могильника. В ходе этих раскопок были обнаружены погребения X-XIV вв. Среди них оказались печенего- 
огузские, половецкие и золотоордынские захоронения. Эти материалы были своевременно опубликованы [Шилов, 1959, с. 510-521] и прочно вошли в золотую кладовую российского и мирового кочевниковедения. Более ранние погребения V-VII вв. в то время рассматривались как позднейшие сармато-аланские захоронения, а погребения VIII-IX вв. еще не были широко известны.

Исследование Астраханской экспедицией подкурганных кочевнических захоронений хазарского времени с необычным обрядом (собственные насыпи) и инвентарем (уникальная золотая арабская монета с граффито, редкое оружие, лепная керамика) с самого начала поставило вопрос их особой этнокультурной атрибуции. Но правильное понимание, однако, пришло не сразу. Могилы из Ордынского бугра Г.А. Федоров-Давыдов отнес к типам Б VI и Б IX [Федоров-Давыдов, 1966, с. 125], но сами памятники рассматривал в рамках первой, в то время наиболее ранней группы комплексов, основу которой составляли заведомо инокультурные печенего-огузские погребения X-XI вв. В качестве древностей салтовского круга подкурганные могилы хазарского времени впервые были определены участниками Новочеркасской археологической экспедиции ЛГУ (рук. Л.С. Клейн) после раскопок в 1971 г. кургана 11 могильника у Соколовской балки [Клейн и др., 1972, с. 132-134]. Надо признать, что на тот момент у ленинградских исследователей для этого имелись несколько более надежные основания, чем у В.П. Шилова. Несмотря на ритуальное разрушение останков погребенного из Соколовского кургана, в сопровождавшем его инвентаре имелись типично салтовский круговой горшок с бороздчатым линейно-волнистым орнаментом и специфические золотые серьги так называемого «салтовского» типа [Круглов, 2013, с. 76 , рис. $2,25,28$ ]. В результате курганные кочевнические захоронения хазарского времени постепенно стали именовать памятниками типа Соколовской балки. Однако, оценивая с позиций уже нашего времени шансы ничем не потревоженных погребений из Ордынского бугра на предмет возможного признания именно их в качестве эпонимных, следует признать, что при наличии своевременной публикации такие шансы могли бы быть более чем высокими. К сожалению, в 60-70-е гг. В.П. Шилов публикацией памятников средневековых кочевников не занимался, хотя и сохранял к ним глубокий научный интерес. В частности, в статье А.А. Быкова воспроизводится мнение, высказанное В.П. Шиловым, что «стремена салтовского типа и обряд захоронения человека со шкурой коня дают возможность определить тюркское происхождение погребенного воина, предположительно хазарина» [Быков, 1974, c. 59]. Поскольку Л.С. Клейн и другие сотрудники Новочеркасской экспедиции вопрос об этнической атрибуции погребения из Соколовского кургана 11 не поставили, именно заключение В.П. Шилова, в пересказе А.А. Быкова, следует считать первым этническим определением памятника соколовского типа в качестве тюркюто-хазарского захоронения.

Опираясь на еще неопубликованные источники, С.А. Плетнева в 1981 г. выделила памятники соколовского типа в третий тип погребений салтово-маяцкой культуры, дав им первую научную характеристику - «подкурганные ямные захоронения, преимущественно в подбойных могилах, окруженные квадратными ровиками». Она также указала на связь этих могил именно с хазарами, отметив, что их обнаружение - «самое крупное открытие в современном хазароведении, сравнимое с результатами работ Волго-Донской экспедиции 19481951 гг.» [Плетнева, 1981, с. 159; 1990, с. 82].

В отличие от С.А. Плетневой, А.И. Семенов отмечал, что памятники соколовского типа характеризуют собой особый, досалтовский период хазарской истории и еще более обоснованно заявлял о связи этих захоронений с социальной верхушкой Хазарского каганата - хазарской знатью, тюркютами рода Ашина, либо с самими хазарами [Семенов, 1978 , c. $182 ; 1983$, c. $98-102 ; 1988$, c. 102-109].

В конце 80-х - начале 1990-х гг. к анализу подкурганных памятников хазарского времени на материалах Волго-Донского междуречья, Сарпинской низменности и Южных Ергеней обращался и автор, также принявший их хазарскую атрибуцию. Для данной территории было признано характерным: практикование захоронений в восточных зонах существующих могильников; ограждение выбранных для производства обрядовых погребально-поминальных действий квадратными или округлыми ровиками; преоб- 
ладание захоронений под индивидуальными насыпями; наличие могил с подбоями в южных стенках входных ям и ступеньками вдоль северных; положение погребенных вытянуто на спине головой на 3; наличие захоронений воинов-лучников; сопровождение погребенных останками ритуальных животных: лошади («взнузданная» и «оседланная» шкура) и барана (шкура или целый остов); наличие жертвенников (сосуд, остатки мясной пищи, ножи) [Круглов, 1989, c. 164-165; 1990, с. 162-164]. В целом эти выводы сохраняют актуальность и сейчас. В то же время осознание необходимости раздельного анализа погребальных и поминальных составляющих обряда проводов человека в иной мир привели к пониманию необходимости более узкой типологической дифференциации имеющегося материала [Круглов, 2013, с. 74-83].

Тюрко-хазарская этническая атрибуция древностей соколовского типа в настоящее время уже не имеет альтернатив. Более сложной оказалась проблема археолого-культурной атрибуции обсуждаемых памятников. Первоначально этот вопрос автор рассматривал с позиции С.А. Плетневой - на основе материалов салтово-маяцкой культуры [Круглов, 1989 , с. $164-165 ; 1990$, с. 162]. Однако определить признаки погребальной обрядности и вещевого инвентаря, которые можно было бы считать бесспорно характерными именно с позиций салтово-маяцкой культуры, не удается. Даже по лепной керамике, как уже отмечалось, вопрос не совсем ясен. Еще в диссертации А.А. Иванова было сделано заключение о том, что типично «салтовские» вещи в погребениях из курганов с ровиками редки и могут рассматриваться наряду с импортными», а также о значительной асинхронности самих групп памятников [Иванов, 1999, c. 65]. Примечательно, что лепные сосуды, по А.А. Иванову, встречаются практически в каждом захоронении. А вот подправленных на круге сосудов с линейно-волнистым орнаментом и столовых серолощеных кувшинов отмечено всего 8 [Иванов, 1999, с. 96-97]. Считать крайне редкую гончарную салтовскую керамику в соколовских погребениях импортом, на наш взгляд, нет оснований, так как это подразумевало бы синхронность памятников и наличие между ними устойчивых границ. А вот разная хронология и общая асинхрон- ность групп памятников (середина VII - начало IX в. и 2-я половина VIII - 1-я половина $\mathrm{X}$ в.) при отсутствии между ними четких ареалов распространения и устойчивых границ объективно существующая реальность.

Автор различает три периода бытования древностей типа Соколовской балки: середина - 2-я половина VII в. ${ }^{7}$; рубеж VII/VIII последняя четверть VIII в.; конец VIII - начало IX в. Отдельные обрядовые характеристики в течение всего этого времени не оставались неизменными. Их соотношение между собой менялось, но почти все изменения объяснимы. Основные обрядовые признаки в целом сохранялись. Наиболее ранние погребения (середина - 2-я половина VII в.) представляют собой впускные могилы в уже существующие курганы или иные природные объекты (дюны, бэровские бугры) с ориентировкой умерших на С-СВ. В настоящее время их обычно рассматривают как погребения так называемого сивашовского типа [Орлов, 1985 , с. 98-105], не разделяя на отдельные группы. Но эпонимный комплекс из Сивашовки устроен в яме со ступеньками вдоль длинных стен [Комар и др., 2006, с. 245-309], что не позволяет считать его характерным для всех погребальных памятников кочевников раннехазарского времени. Могилы с подбоями (группа Бережновка (кург. 111) - Виноградное (кург. 5) - Портовое) могут и должны рассматриваться в качестве раннесоколовских. Именно на их основе к рубежу VII/VIII вв. и сформировались древности типа Соколовской балки [Круглов, 2013, с. 80-81]. Основное количество захоронений этого типа датируется рубежом VII/VIII - концом VIII в. К финалу именно этого, второго периода, относятся и оба погребения из могильника Ордынский бугор. Золотой арабский динар определяет для них terminus ante quem - условную абсолютную нижнюю дату - 760/761 г., а относительной можно считать 2-ю половину 3-й - начало 4-й четверти VIII в. Примечательно, что эта дата перекрывает время появления салтово-маяцкой культуры в Доно-Донецком регионе и показывает, что одновременного распространения салтовских вещей на всей территории Хазарского каганата не было. Вопрос соотношения памятников соколовского типа и салтово-маяцкой культуры пока следует оставить открытым. 


\section{ИЛЛЮСТРАЦИИ}

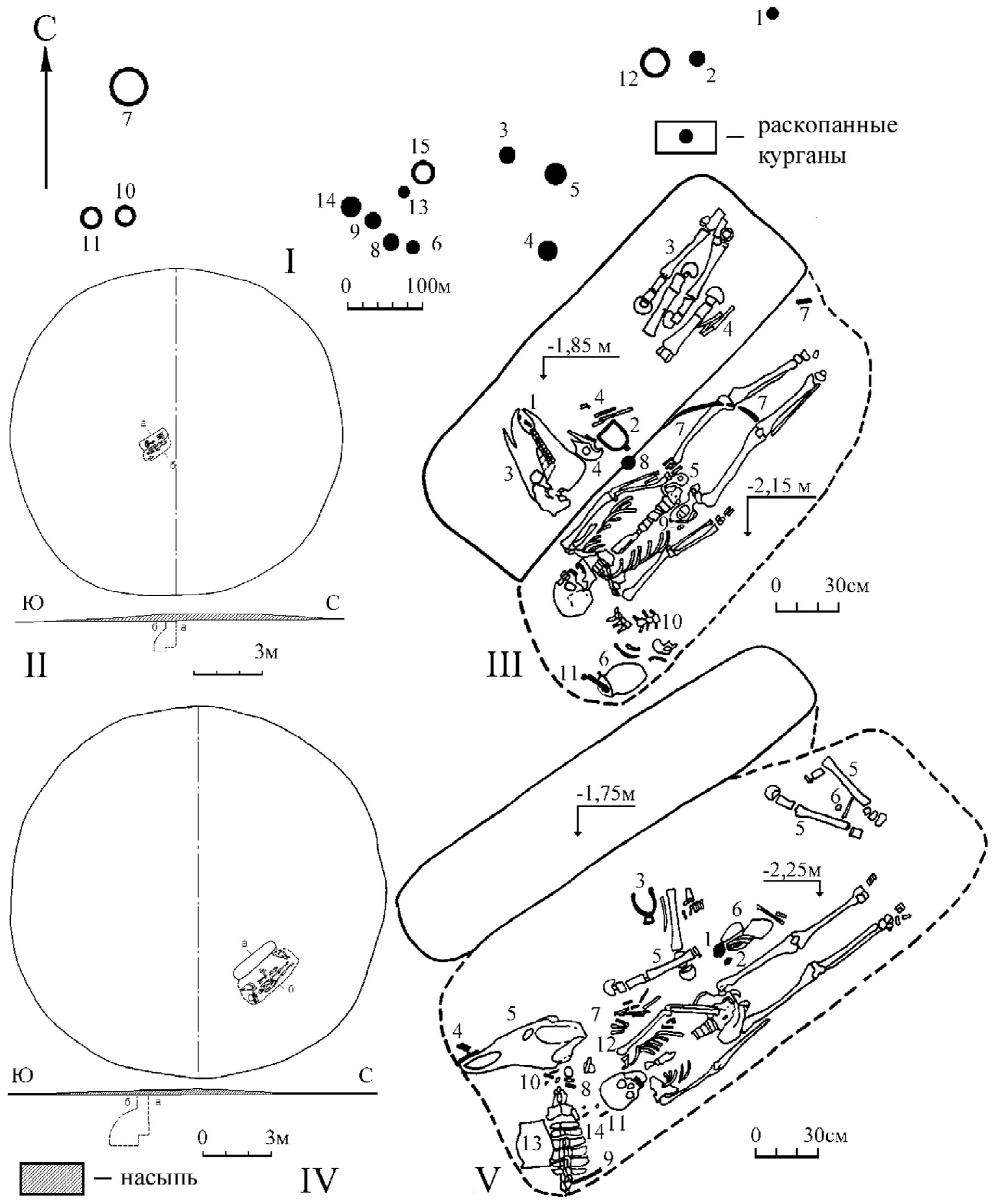

Рис. 1. I- план курганного могильника Ордынский бугор; II, III - погребение 1 из кургана 4; $I V, V$ - погребение 1 из кургана 13. $I-V$ по: [Маловицкая, 1963]

Fig. 1. $I$ - a plan of the Ordynsky bugor burial mound; $I I, I I I$ - burial 1 from barrow 4; $I V, V$ - burial 1 from barrow 13. I-V in [Malovitskaia, 1963] 


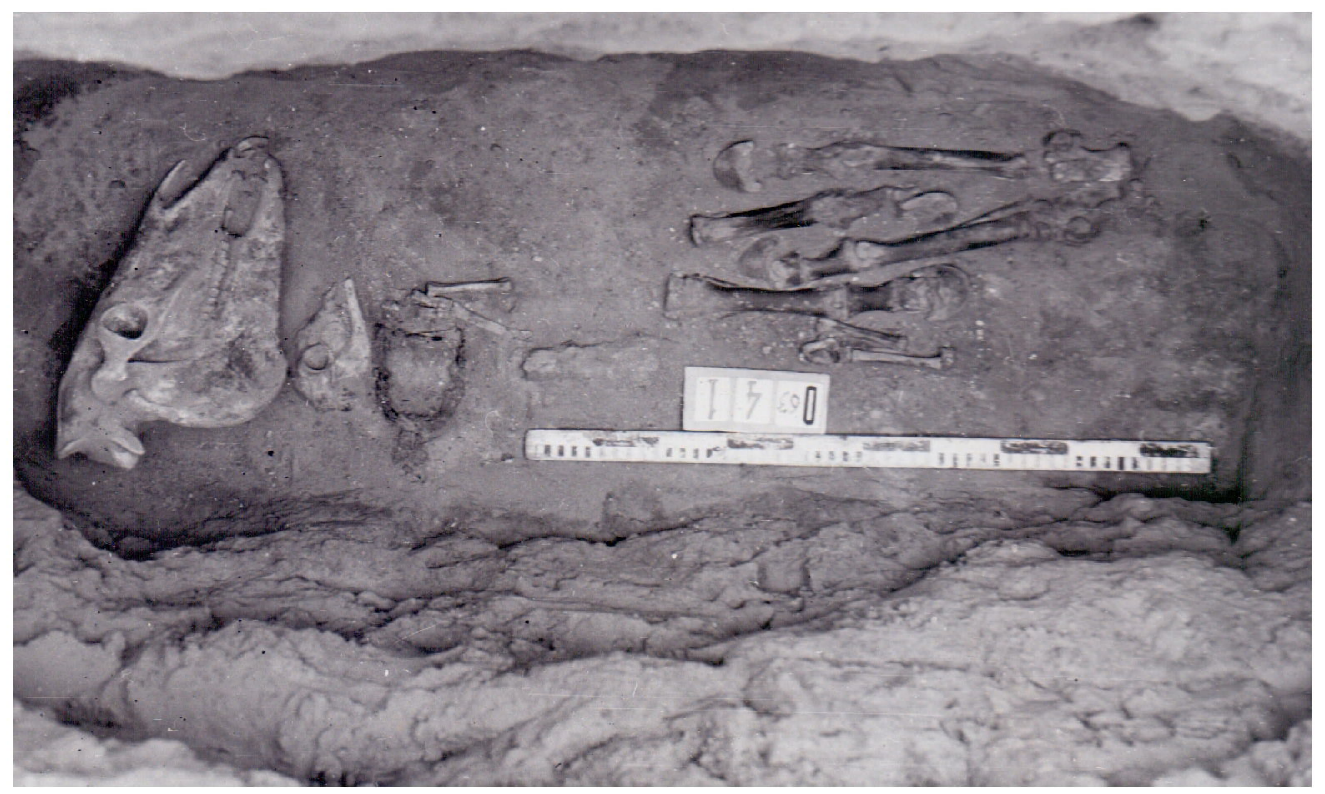

1

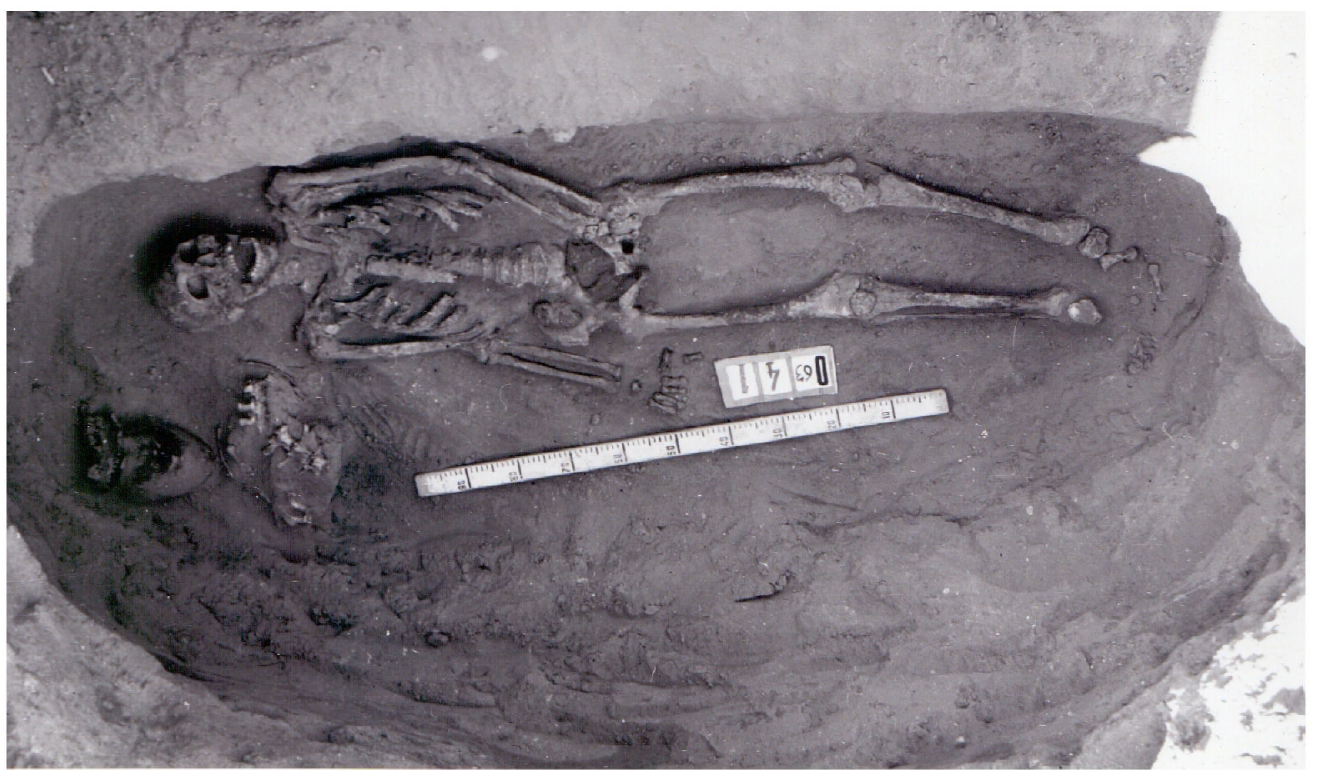

2

Рис. 2. 1, 2 - фотографии погребения 1 из кургана 4 могильника Ордынский бугор (вид с юго-востока), по: [Маловицкая, 1963]

Fig. 2. 1,2-photographs of burial 1 from barrow 4 of the Ordynsky bugor burial mound (south-east view), in [Malovitskaia, 1963] 
E.V. Kruglov. The Formation of the Source Base of Sokolovskaya Balka Type Monuments

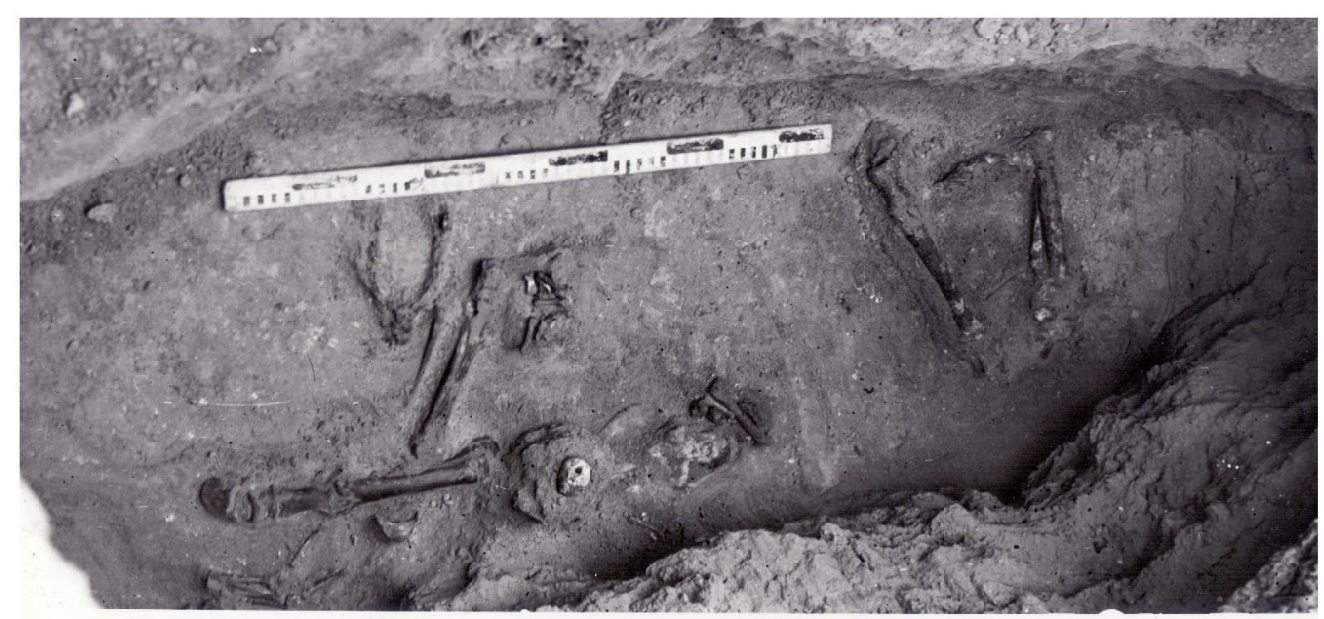

1

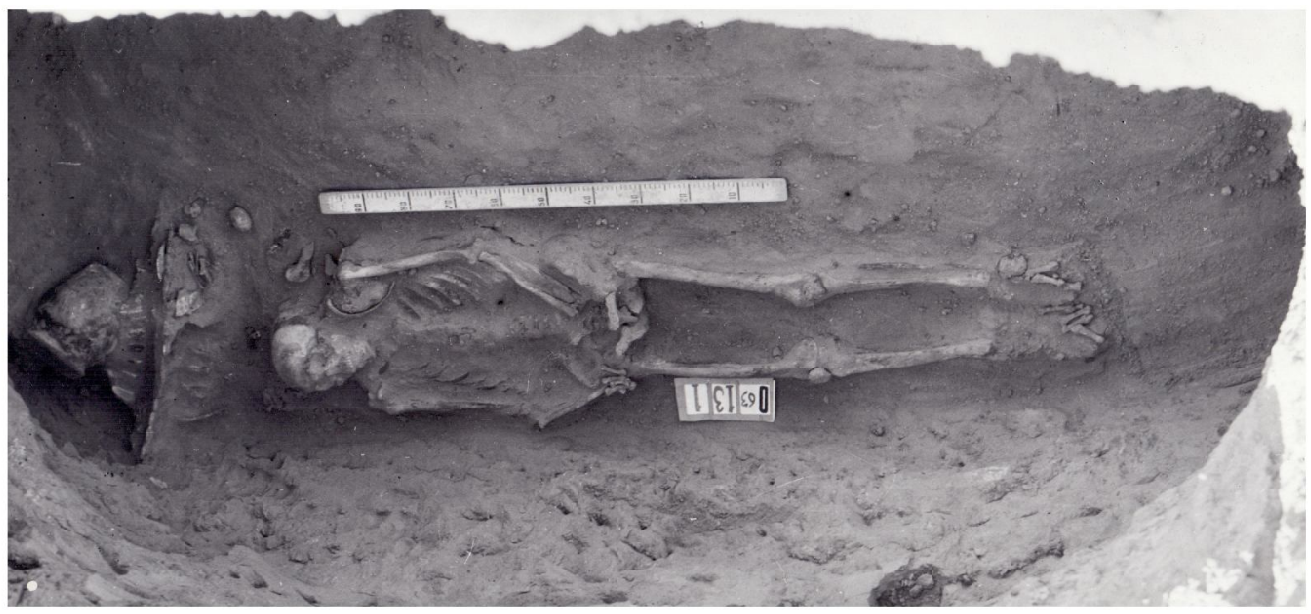

2

Рис. 3. 1, 2- фотографии погребения 1 из кургана 13 могильника Ордынский бугор (вид с юго-востока), по: [Маловицкая, 1963]

Fig. 3. 1,2-photographs of burial 1 from barrow 13 of the Ordynsky bugor burial mound (south-east view), in [Malovitskaia, 1963] 

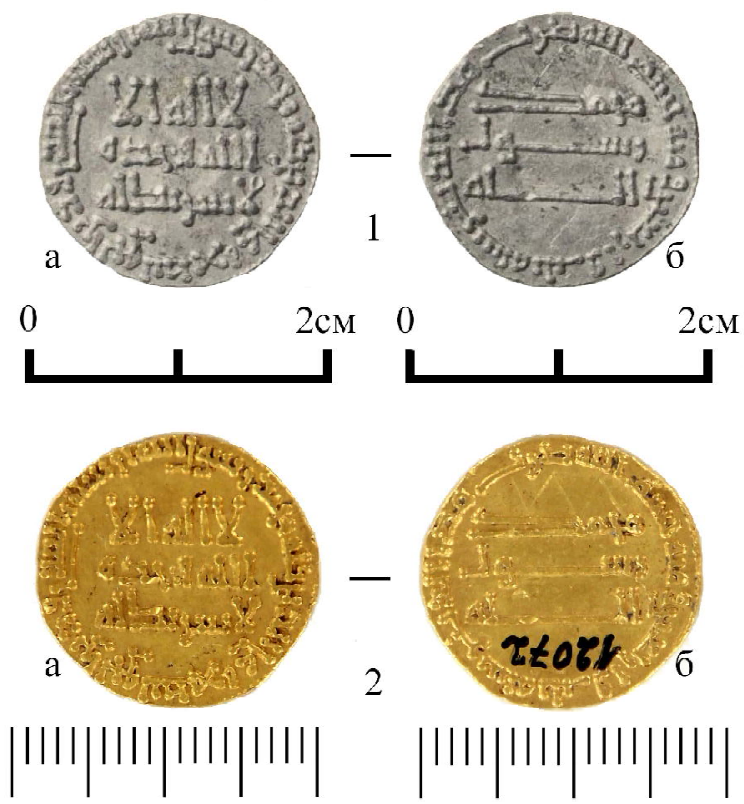

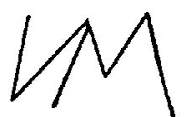

a

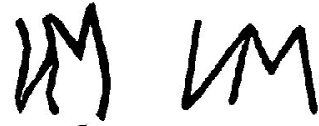

б
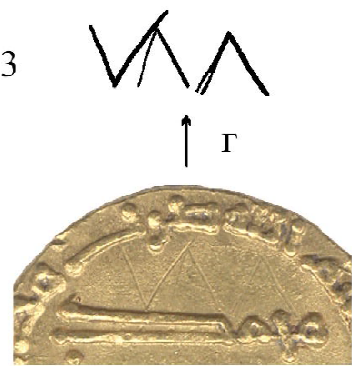

Д

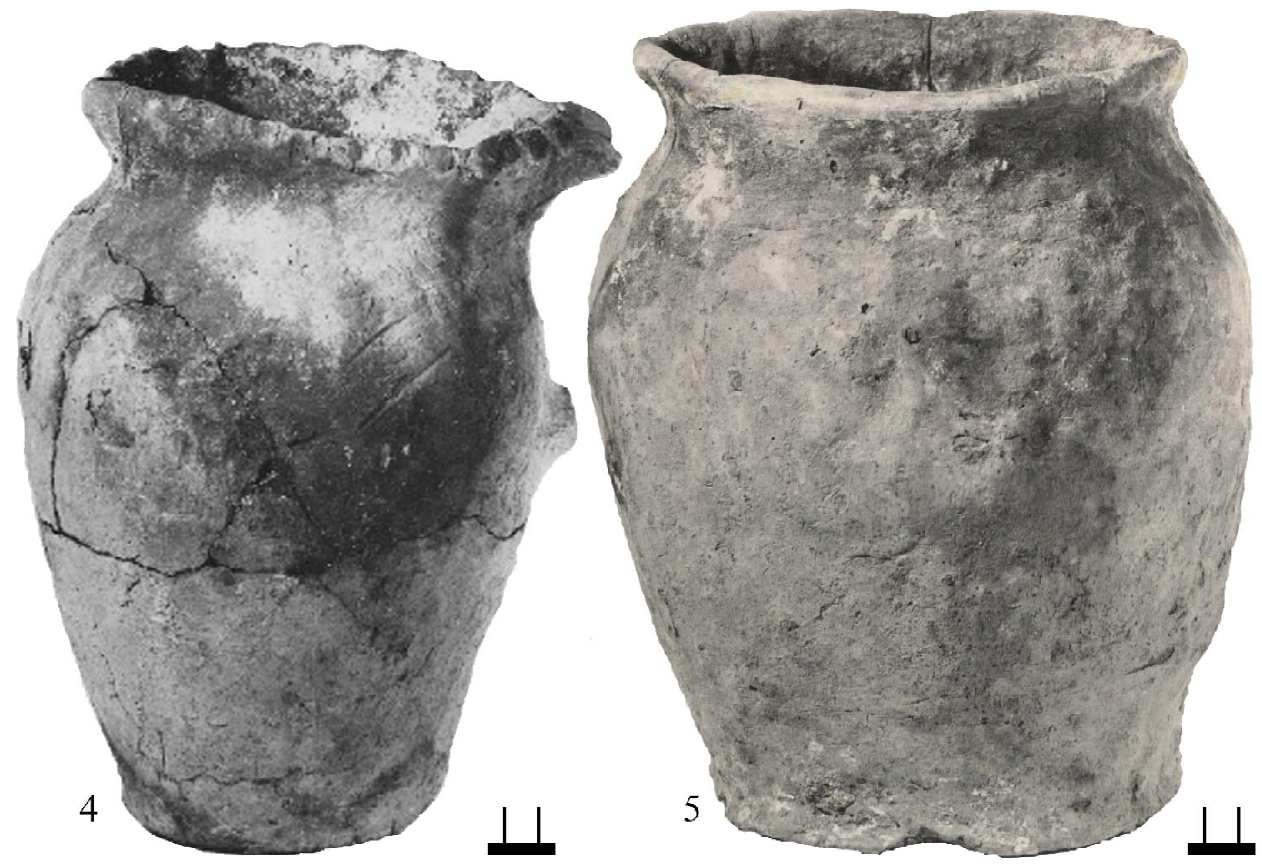

Рис. 4. 1, 2 - арабский динар ал-Мансура Аббасида: 1 - фотография по: [Маловицкая, 1963];

2 - фотография Э.Р. Чиняковой (Сейфетдиновой), инв. № АМЗ КП 12072 (2018 г.);

3 - прорисовки граффито на монете: $a$ - по: [Быков, 1974], 6 , в - по: [Добровольский и др., 1981] и [Добровольский и др., 1991]; г, $\partial$ - автора по фотографии Э.Р. Чиняковой (Сейфетдиновой); 4 - кувшин;

5 - сосуд. 1-4 - погребение 1 кургана 4; 5 - погребение 1 кургана 13. 1, 2 - золото; 3 - граффито; 4, 5 - глина

Fig. 4. 1,2-the Arab dinar of al-Mansur: 1-a photograph in [Malovitskaia, 1963]; 2 - a photograph by E.R. Chinyakova (Seifetdinova), inventiry no. AMZ KP 12072 (2018);

3 -drawings of a graffito on the coin: $a$-in: [Bykov, 1974], $b, v$-in: [Dobrovolskiy et al., 1981] and [Dobrovolskiy et al., 1991]; $g, d$ - author's on the basis of a photograph by E.R. Chinyakova (Seyfetdinova); 4 - jar; 5 - vessel. $1-4$ - burial 1 from barrow 4; 5 - burial 1 from barrow 13.1, 2- gold; 3 - graffito; 4,5 - clay 


\section{ПРИМЕЧАНИЯ}

1 Данное сообщение посвящается памяти кандидата исторических наук В.П. Шилова. Прочитано и обсуждено в качестве доклада на научной конференции «“Диалог культур: Восток - Запад”. К 100-летию со дня рождения Валентина Павловича Шилова. г. Волгоград, 7-10 февр. 2018 г. / организаторы: ВолГУ и ВОКМ. Волгоград, 2018».

${ }^{2}$ Номера планов соответствуют научному отчету Л.Я. Маловицкой.

${ }^{3}$ Могильный инвентарь, хранящийся в фондах АГОИАМЗ, частично был осмотрен автором в 1984 г.

${ }^{4}$ Фотографии и сканированные изображения современного вида динара были любезно предоставлены Э.Р. Чиняковой (Сейфетдиновой), заведующей отделом фондов, хранителем коллекции предметов из драгоценных металлов и камней, научным сотрудником АГОИАМЗ, за что выражаю ей глубокую признательность.

${ }^{5}$ Есть и другие работы.

${ }^{6}$ Письма Вяч.С. Кулешова и И.Л. Кызласова к автору от 25.032018 г. Признателен Вяч.С. Кулешову и И.Л. Кызласову за ценные консультации.

${ }^{7}$ Выделение раннего периода в настоящее время пока дискуссионно.

\section{СПИСОК ЛИТЕРАТУРЫ}

Афанасьев Г. Е., 2013. Отощители в формовочной массе кухонной посуды салтово-маяцкой культуры как этномаркирующий признак // Очерки средневековой археологии Кавказа. К 85-летию со дня рождения В.А. Кузнецова. М. : ИА РАН. С. 34-50.

Быков А. А., 1974. Из истории денежного обращения Хазарии в VIII и IX вв. // Восточные источники по истории народов Юго-Восточной и Центральной Европы. Т. ІІІ. М. : Вост. лит. С. 26-71.

Добровольский И. Г., Дубов И. В., Кузьменко Ю. К., 1981. Классификация и интерпретация граффити на восточных монетах (коллекция Эрмитажа) // Труды Государственного Эрмитажа. Т. ХХІ. Л. : Искусство, Ленингр. отд-ние. С. 53-77.

Добровольский И. Г., Дубов И. В., Кузьменко Ю. К., 1991. Граффити на восточных монетах. Древняя Русь и сопредельные страны. Л. : Изд-во ЛГУ. $192 \mathrm{c.}$

Иванов А. А., 1999. Раннесредневековые подкурганные кочевнические захоронения второй половины VII - первой половины IX в. Нижнего Дона и Волго-Донского междуречья : дис. ... канд. ист. наук. Волгоград. 252 с. // Архив кафедры археологии ВолГУ.

Клейн Л. С., Раев Б. А., Семенов А. И., Субботин А. В., 1972. Катакомба скифского времени и салтовский курган на Дону // Археологические открытия - 1971 г. М. : Наука. С. 132-134.

Комар А. В., Кубышев А. И., Орлов Р. С., 2006. Погребения кочевников VI-VII вв. из Северо-Западного Приазовья // Степи Европы в эпоху средневековья. Т. 5. Донецк : Изд-во ДонНУ. C. 245-374.

Кропоткин В. В., 1968. Новые материалы по истории денежного обращения в Восточной Европе в конце VIII - первой половине IX в. // Славяне и Русь. М. : Наука. С. 72-79.

Круглов Е. В., 1989. К вопросу об этнокультурной характеристике подкурганных погребений салтово-маяцкой культуры (по материалам восточной группы памятников) // Проблемы охраны и исследования памятников археологии в Донбассе. Донецк. С. 164-165.

Круглов Е. В., 1990. О подкурганных захоронениях калмыцко-астраханских степей хазарского времени // Вопросы археологии юга Восточной Европы. Элиста : Изд-во КалмГУ. C. $159-171$.

Круглов Е. В., 2002. Некоторые проблемы анализа особенностей обращения византийских монет VI-VIII вв. в восточноевропейских степях // Хазарский альманах. Т. 1. Харьков : Каравелла. С. 79-93.

Круглов Е. В., 2004. Обращение византийских и арабских монет в Хазарском каганате в VIII в. и их датирующие возможности // Двенадцатая Всероссийская нумизматическая конференция. Москва, 19-24 апр. 2004 г. М. : Изд-во ГИМ. С. 52-54.

Круглов Е. В., 2005. Сложносоставные луки Восточной Европы раннего средневековья // Степи Европы в эпоху средневековья. Т. 4. Донецк : Изд-во ДонНУ. С. 73-142.

Круглов Е. В., 2013. О курганах с ровиками, погребениях типа Соколовской балки и некоторых иных древностях хазарского времени (к постановке проблемы) // Город и степь в контактной Евро-Азиатской зоне : материалы III Междунар. науч. конф., посвящ. 75-летию со дня рождения профессора Г.А. ФедороваДавыдова (1931-2000). Труды ГИМ. Вып. 184. М. : Изд-во ГИМ. С. 74-83.

Кулешов Вяч. С., 2009. О распространении золотых куфических монет VIII в. в Восточной Европе // Пятнадцатая Всероссийская нумизматическая конференция. Ростов н/Д, 20-25 апр. 2009 г. М. : Изд-во ГИМ. С. 59-61. 
Кулешов Вяч. С., 2012. Комплекс умаййадских монет Элмедского клада и его выдающееся историко-культурное значение // Труды Камской археолого-этнографической экспедиции. Вып. VIII. Пермь. С. 218-227.

Кулешов Вяч. С., 2016. Периодизация монетного обращения середины VIII - начала XI в. в Восточной Европе и динамика экономических связей древнейших русских дружин // Управленческое консультирование. № 2. С. 169-179.

Маловицкая Л. Я., 1963. Отчет о раскопках Астраханской археологической экспедиции в 1963 г. // Архив ИА РАН. Р-1. № 2750, а.

Орлов Р. С., 1985. Культура кочевников IV-VIII вв. // Этнокультурная карта территории Украинской ССР в І тыс. н.э. Киев : Наукова Думка. С. 98-105.

Плетнева С. А., 1967. От кочевий к городам. Салтово-маяцкая культура // МИА СССР. Т. 142. М. : Наука. 198 c.

Плетнева С. А., 1981. Салтово-маяцкая культура // Степи Евразии в эпоху средневековья. М. : Наука. C. 62-75.

Плетнева С. А., 1990. Проблемы хазарской археологии // СА. № 2. С. 77-91.

Рыков П. С., 1936. Очерки по истории Нижнего Поволжья по археологическим материалам. Саратов : Сарат. краевое изд-во. $152 \mathrm{c}$.

Семенов А. И., 1978. Византийские монеты из погребений хазарского времени на Дону // Проблемы археологии. Вып. 2. Л. : Изд-во ЛГУ. С. $180-183$.

Семенов А. И., 1983. Романовское погребение и донские памятники предсалтовской культуры хазарского времени // Проблемы хронологии археологических памятников степной зоны Северного Кавказа. Ростов н/Д. С. 98-102.

Семенов А. И., 1988. К выявлению центральноазиатских элементов в культуре раннесредневековых кочевников Восточной Европы // Apхеологический сборник. Вып. 29. Л. : Искусство, Ленингр. отд-ние. С. 97-111.

Тизенгаузен В. Г., 1873. Монеты Восточного Халифата. Спб. : Тип. Императорской Академии наук. $374 \mathrm{c.}$

Федоров-Давыдов Г. А., 1966. Кочевники Восточной Европы под властью золотоордынских ханов. М. : Изд-во МГУ. 274 с.

Шилов В. П., 1959. Калиновский курганный могильник // МИА СССР. Т. 60. М. : Изд-во АН СССР. C. 323-523.

\section{REFERENCES}

Afanas'ev G.E., 2013. Leaners in the molding composition of cooking utensils of the Saltovo-
Mayatsk culture as an ethnicity-indicating factor. Ocherki srednevekovoi arkheologii Kavkaza. K 85-letiiu so dnia rozhdeniia V.A. Kuznetsova. Moscow, Institute of Archaeology of RAS, pp. 34-50. (in Russian).

Bykov A.A., 1974. From the history of Khazar money circulation in the $8^{\text {th }}-9^{\text {th }} \mathrm{cc}$. Vostochnye istochniki po istorii narodov Iugo-Vostochnoi i Tsentralnoi Evropy. Vol. III. Moscow, Vostochnaia literatura Publ., pp. 26-71. (in Russian).

Dobrovol'skij I.G., Dubov I.V., Kuz'menko Yu.K., 1981. Classification and interpretation of graffiti on Eastern coins (the Hermitage collection). Trudy Gosudarstvennogo Ermitazha. Vol. XXI. Leningrad, Iskusstvo Publ., Leningradskoe otdelenie, pp. 53-77. (in Russian).

Dobrovol'skiy I.G., Dubov I.V., Kuz'menko Yu.K., 1991. Graffiti on Eastern coins. Ancient Rus' and neighbouring countries. Leningrad, Izd-vo LGU. 192 p. (in Russian).

Ivanov A.A., 1999. Early medieval burial complexes of nomads in the second half of VII c. - the first half of IXc. in the territory the Lower Don and the Volga-Don interfluve. Cand. hist. sci. diss. Volgograd. 252 p. (in Russian).

Klejn L.S., Raev B.A., Semenov A.I., Subbotin A.V., 1972. Catacomb of the Scythian age and the Saltovo kurgan on Don. Arkheologicheskie otkrytiia - 1971. Moscow, Nauka Publ., pp. 132134. (in Russian).

Komar A.V., Kubyshev A.I., Orlov R.S., 2006. Nomad burials of VI-VII c. from North-West Azov reaches. The European Steppes in the Middle Ages. Vol. 5. Donetsk, DonNU, pp. 245-374. (in Russian).

Kropotkin V.V., 1968. New materials on the history of coin circulation in Eastern Europe in the late $8^{\text {th }}$ - first half of the $9^{\text {th }}$ cc. Slaviane $i$ Rus'. Moscow, Nauka Publ., pp. 72-79. (in Russian).

Kruglov E.V., 1989. About the ethnocultural characteristic of sub-kurgan burials of the Saltovo-Mayatsk culture (based on the materials on Eastern monuments group). Problemy okhrany $i$ issledovaniia pamiatnikov arkheologii v Donbasse. Donetsk, pp. 164-165. (in Russian).

Kruglov E.V., 1990. About the sub-kurgan burials of Kalmyk-Astrakhan steppes of the Khazar age. Voprosy arkheologii iuga Vostochnoi Evropy. Elista, Kalmyk State University, pp. 159-171. (in Russian).

Kruglov E.V., 2002. Some problems of analyzing the particularities of Byzantine $6^{\text {th }}-8^{\text {th }}$ cc. coins circulation in Easter European steppes. Khazarskii almanakh. Vol. 1. Kharkov, Karavella Publ., pp. 79-93. (in Russian). 
Kruglov E.V., 2004. The circulation of Byzantine and Arab coins in the Khazar Khaganate in $8^{\text {th }}$ century and their date establishing properties. Dvenadtsataia Vseros. numizmat. konf. Moskva, 19-24 apr. 2004 g. Moscow, Izd-vo GIM, pp. 52-54. (in Russian).

Kruglov E.V., 2005. Compound-complex bows of early mediaeval Eastern Europe. The European Steppes in the Middle Age. Vol. 4. Doneck, Izdvo DonNU, pp. 73-142. (in Russian).

Kruglov E.V., 2013. About "mounds with moats", the burials for example "Sokolovskoi balki" and some other artifacts of Khazar period (to the problem setting). Gorod $i$ step v kontaktnoi Evro-Aziatskoi zone: materialy III Mezhdunar. nauch. konf., posviashch. 75-letiiu so dnia rozhdeniia professora G.A. FedorovaDavydova (1931-2000). Trudy GIM. Iss. 184. Moscow, Izd-vo GIM, pp. 74-83. (in Russian).

Kuleshov Viach.S., 2009. About the distribution of golden Cufic coins dated $8^{\text {th }}$ century in Eastern Europe. Piatnadtsataia Vserossiiskaia numizmaticheskaia konferentsiia. Rostov-naDonu, 20-25 apr. 2009 g. Moscow, Izd-vo GIM, pp. 59-61. (in Russian).

Kuleshov Viach.S., 2012. The body of Umayyad coins of the Jelmedsky treasure and its outstanding historical-cultural value. Trudy Kamskoi arkheologo-etnograficheskoi ekspeditsii. Iss. VIII. Perm', pp. 218-227. (in Russian).

Kuleshov Viach.S., 2016. Periodization of coin circulation of the mid $-8^{\text {th }}$ to the beginning of the $11^{\text {th }} \mathrm{cc}$. in Eastern Europe and the dynamics of economic relations between the oldest Russian druzhinas. Upravlencheskoe konsultirovanie, no. 2, pp. 169-179. (in Russian).

Malovickaya L.Ya., 1963. The report on the Astrakhan archaeological expedition excavations in 1963. Archive of Institute of Archaeology of RAS, R-1, no. 2750, a. (in Russian).

Orlov R.S., 1985. The culture of IV-VIII age nomads. Etnokulturnaia karta territorii Ukrainskoi SSR v I tys. n.e. Kiev, Naukova Dumka Publ., pp. 98-105. (in Russian).

Pletneva S.A., 1967. From nomads to the cities. Saltovo-Mayaki culture. Materialy $i$ issledovanija po arheologii SSSR. Vol. 142. Moscow, Nauka Publ. 198 p. (in Russian).
Pletneva S.A., 1981. Saltovo-Mayaki culture. Stepi Evrazii v epokhu srednevekovia. Moscow, Nauka Publ, pp. 62-75. (in Russian).

Pletneva S.A., 1990. Problems of Khazar archaeology. Sovetskaja arkheologiya, no. 2, pp. 77-91. (in Russian).

Rykov P.S., 1936. Essays on the history of the Lower Volga Region. Based on archaeological materials. Saratov, Sarat. kraevoe izd-vo. 152 p. (in Russian).

Semenov A.I., 1978. Byzantine coins from the Khazar age burials on Don. Problemy arkheologii. Iss. 2. Leningrad, Izd-vo LGU, pp. 180-183. (in Russian).

Semenov A.I., 1983. The Romanov village burial and Don memorials of the pre-Saltov culture of the Khazar age. Problemy khronologii arkheologicheskikh pamiatnikov stepnoi zony Severnogo Kavkaza. Rostov-on-Don, pp. 98102. (in Russian).

Semenov A.I., 1988. About the discovery of CentralAsian elements in the culture of Early Medieval nomads of Eastern Europe. Arkheologicheskii sbornik. Iss. 29. Leningrad, Iskusstvo Publ., Leningradskoe otdelenie, pp. 97-111. (in Russian).

Tizengauzen V.G., 1873. Coins of the Eastern Caliphate. Sankt-Peterburg, Tipografiia Imperatorskoi Akademii nauk. 374 p. (in Russian).

Fedorov-Davydov G.A., 1966. Nomads of Eastern Europe under the power of khans of Golden Horde. Moscow, Izd-vo Moskovskogo universiteta. 274 p. (in Russian).

Shilov V.P., 1959. Kalinovskij kurgannyj mogil'nik. Materialy i issledovaniia po arkheologii SSSR. Vol. 60. Moscow, Izd-vo AN SSSR, pp. 323-523. (in Russian).

\section{СПИСОК СОКРАЩЕНИЙ}

АГОИАМЗ - Астраханский государственный объединенный историко-архитектурный музейзаповедник.

ГИМ - Государственный исторический музей.

МИА СССР - Материалы и исследования по археологии СССР.

$\mathrm{CA}$ - Советская археология. 


\section{Information about the Author}

Evgeniy V. Kruglov, Secretary, Volgograd Regional Department of All-Russian Community for Nature and Culture Monuments Protection, Kaleganova St., 9, office 107, 400081 Volgograd, Russian Federation, khasar@vlpost.ru.

\section{Информация об авторе}

Евгений Викторович Круглов, секретарь, Волгоградское региональное отделение Всероссийского общества охраны памятников истории и культуры Волгоградской области, ул. им. Калеганова, 9, офис 107, 400081 г. Волгоград, Российская Федерация, khasar@vlpost.ru. 